\title{
Leafcutter Ant Nests Inhibit Low-Intensity Fire Spread in the Understory of Transitional Forests at the Amazon's Forest-Savanna Boundary
}

\author{
Karine S. Carvalho, ${ }^{1}$ Ane Alencar, ${ }^{2}$ Jennifer Balch, ${ }^{3,4,5}$ and Paulo Moutinho ${ }^{2}$ \\ ${ }^{1}$ Departamento de Ciências Biológicas, Universidade Estadual do Sudoeste da Bahia, Avenida José Moreira Sobrinho, \\ 45206-190 Jequié, BA, Brazil \\ ${ }^{2}$ Instituto de Pesquisa Ambiental da Amazônia, Avenida Nazaré 669, 66035-170 Belém, PA, Brazil \\ ${ }^{3}$ Woods Hole Research Center, 149 Woods Hole Road, Falmouth, MA 02450, USA \\ ${ }^{4}$ National Center for Ecological Analysis and Synthesis, 735 State Street, Santa Barbara, CA 93101, USA \\ ${ }^{5}$ Department of Geography, The Pennsylvania State University, 302 Walker Building, University Park, PA 16802, USA
}

Correspondence should be addressed to Karine S. Carvalho, ksczool@yahoo.com.br

Received 11 March 2011; Accepted 13 June 2011

Academic Editor: Jonathan D. Majer

Copyright (c) 2012 Karine S. Carvalho et al. This is an open access article distributed under the Creative Commons Attribution License, which permits unrestricted use, distribution, and reproduction in any medium, provided the original work is properly cited.

\begin{abstract}
Leaf-cutter ants (Atta spp.) remove leaf litter and woody debris—potential fuels—in and around their nests and foraging trails. We conducted single and three annual experimental fires to determine the effects of this leaf-cutter ant activity on the behavior of low-intensity, slow-moving fires. In a transitional forest, where the southern Amazon forest meets the Brazilian savanna, we tested whether leaf-cutter ant nests and trails (i) inhibit fire spread due to a lack of fuels, and (ii), thereby, reduce the total burned area during these experimental low-intensity fires, particularly at forest edges where leaf-cutter ant abundance was higher. Finemedium fuel mass increased with an increase in distance from ant nest, and the mean area of bare soil was greater on nests than on the forest floor. Between 60 to 90 percent of the unburned area was within $30 \mathrm{~m}$ of ant nests, and burned area significantly increased with increasing distance to ant nests. In addition, the number of ant nests declined with increasing distance from the forest edge, and, with exception of the first experimental fire, burned area also increased with increasing distance from the edge. The present study provides new insight to fire ecology in Amazon environments.
\end{abstract}

\section{Introduction}

Leaf-cutter ants (Atta spp.) are considered conspicuous herbivores in the neotropics $[1,2]$. Their role in the ecosystem, however, goes well beyond their herbivory because their construction and maintenance of nests causes diverse impacts to soil $[3,4]$ with consequences for recruitment dynamics, [5-9] nutrient access $[10,11]$, and growth of nearby vegetation [12].

Impacts caused by leaf-cutter ants, or bioperturbation, are associated with their behavior of cultivating symbiotic fungus in subterranean chambers linked through a network of tunnels [13-15]. In order to build these chambers, worker ants remove soil to depths up to $7 \mathrm{~m} \mathrm{[16]} \mathrm{and} \mathrm{deposit} \mathrm{it} \mathrm{on}$ the soil surface, forming a mound, a characteristic heap of soil $[15,17,18]$.
During ant nest excavation and expansion, the leaf litter and nearby seedlings are buried or removed, which effectively leaves the mound completely bare. Moreover, the worker ants remove debris near the nest (and along foraging trails) as part of their maintenance activities and thereby leave the nest area free of small plants and debris $[7,19,20]$.

Therefore, leaf-cutter ants are considered resilient to fire because they (1) consume leaf biomass, often $12-17 \%$ of annual production of a tropical forest $[1,21-23]$, which is potential fuel; (2) construct subterranean nests out of nonflammable materials, for example, soil; (3) clear trails to bare mineral soil, which are effectively firebreaks for low-intensity fires. Moreover, leaf-cutting ants regulate the temperature of the fungus garden by opening or closing entrances to the nest or by modifying the culture's location inside the nest during different times of the year $[2,24]$. These combined effects 
may allow leaf-cutter ants to avoid immediate fire damage. However, the longer-term consequences of fire, for example, habitat modification, food availability, and so forth, are not tested or discussed in this study.

Leaf cutter ants are more abundant in disturbed habitats [25-28] with degraded edges [22, 29-31]. These habitats are dominated by pioneers which have less defenses against herbivory $[25,26,32,33]$. Based on that assumption, we propose to address the following questions: can leaf-cutter ants inhibit fire and effectively protect nearby vegetation in a forest that has experienced this type of disturbance? And if the answer is yes, is this protection more effective at the forest edge? In order to respond to these questions, we hypothesize that leaf-cutter ant trails and nest building (i) blocks fire spread by removing potential fuels and therefore (ii) reduces the total burned area, especially at the forest edge, where they are more abundant.

\section{Methods}

2.1. Study Site. The study was conducted in seasonally dry forests of the southern Amazon basin on Tanguro Ranch, Mato Grosso, Brazil $\left(13^{\circ} 04^{\prime} 35.39^{\prime \prime} \mathrm{S}, 52^{\circ} 23^{\prime} 08.85^{\prime \prime} \mathrm{W}\right)$. The forest biome is at the Cerrado-Amazônia ecotone, and is described as the dry forests of Mato Grosso [34]. In this region, a severe dry season occurs between May and September, while the rainy season occurs between October and April. Annual mean temperature is $23.5^{\circ} \mathrm{C}$ with annual precipitation between 1800 to $2000 \mathrm{~mm}$ [35].

This study is part of the "Savannization" project created in 2004 by the Amazon Environmental Research Institute (IPAM) and the Woods Hole Research Center (WHRC), with the objective of evaluating the effects of repeated understory wildfires on the susceptibility of forests to future fires. In the context of this greater project, we worked within a 150 ha experimental block divided into three 50 ha treatments, defined as: plot (a) unburned control; plot (b) once-burned; and plot (c) thrice-burned. The scale at which wildfires occur in the Amazon required a large-scale ecosystem approach, which makes adequate experimental replication challenging [36]. A necessary limitation of this experiment is that we treat sampling within the 50 ha treatment plots as independent, which we acknowledge as a form of pseudoreplication that is often associated with experimental fires [37]. Moreover, conducting the experimental burns required that the burned plots be adjacent, and therefore treatment was not randomly assigned to each 50 ha block.

Three annual experimental burns were conducted in August or September (2004-6), near the end of the dry season, when many escaped wildfires typically occur (see [35] for a complete description of the site, experimental design, and fire behavior). During all burns, mean daily temperature ranged between 24 to $29^{\circ} \mathrm{C}$, and relative humidity ranged between 51 to $57 \%$ (measured at the meteorological station). Wind speed was low in the understory $(<0.5 \mathrm{~m} / \mathrm{s})$ and had little noticeable effect on fire behavior during all years. Fires were set with kerosene drip torches; a total of $10 \mathrm{~km}$ of fire lines were set per plot during three to four consecutive days between $9: 00 \mathrm{~h}$ and 16:00 h. During all years, fires were extinguished at night and were relit on subsequent days. Combining both burn plots, initial mean flame height and fire spread rate (FSR; \pm SE) were $31( \pm 1) \mathrm{cm}$ and 0.21 $( \pm 0.01) \mathrm{m} / \mathrm{min}$, demonstrating that these experimental fires were low-intensity and slow-moving. It is worth noting that fire intensity and spread significantly declined during the second and third burn [35]. Compared with the first burn in 2004, mean flame heights declined by $\sim 10 \mathrm{~cm}$ in subsequent burns, and the burned area declined by half in the third fire [35].

\subsection{Measurement of Fire Inhibition of Ant Nests and Trails.} In order to test the effect of ant nests on fire spread, two measurements were taken: (i) quantification of the amount of fine and small-medium woody fuels (defined here as leaves and twigs with diameter $\leq 5 \mathrm{~cm}$ ) which dry faster than large woody debris on the forest floor on and near ant nest mounds and soil, and (ii) calculation of the total area of bare soil created by nests and trails.

Measurement of fuels was conducted between August and September 2005, within several weeks before the experimental fires of that year. For this part of the study, only the experimental burn plots were used (plots (b) and (c)), and all mature, inventoried Atta ant nests within the limits of these two plots were utilized (plot $(\mathrm{b})=11$ nests and plot $(\mathrm{c})=4$ nests).

Maximum height of small twigs was measured within a $40 \mathrm{~cm}$ diameter metal ring with increasing distance from each ant nest. Six rings were distributed along a $15 \mathrm{~m}$ transect, starting from the nest center $(0 \mathrm{~m})$ and extending 3 , $6,9,12$, and $15 \mathrm{~m}$ from the nest. After measuring fuel height, all the leaf litter fuels within the $40 \mathrm{~cm}$ diameter ring were collected and dried in an oven at $50^{\circ} \mathrm{C}$ for 48 hours.

To quantify the amount of bare soil associated with ant nests, a wooden frame $(100 \times 20 \mathrm{~cm})$ was thrown in the nest center and in the nest extremes point. The area within the frame of covered and bare soil was noted. In addition, the length and width of the foraging trails of six nests were measured to calculate the average total area of bare soil associated with a single nest and thereby infer the total forest floor area that was inflammable due to an absence of fuels.

\subsection{Relationship between Nest Abundance and Unburned} Areas. In order to determine whether ant nests reduce the forest burned area, the annual burn plot (plot (c)) was selected because it was the only one that permitted comparisons between years $(2004,2005$, and 2006) and was appropriate for the time period of the present study.

The location of the existing ant nests in the experimental area was registered with an inventory conducted in February of 2005. This inventory used the existing 31 transects (N-S trails which were cut every $50 \mathrm{~m}$ in July 2004) in the 150 ha area (each transect was $1 \mathrm{~km}$ in length and $40 \mathrm{~m}$ in width, totaling a "scanned" area of $116 \mathrm{ha}$ ). All of the present ant nests of Atta species that were seen within these transects were registered, mapped, and classified.

Nests were classified as active (when ants responded to the stimulus provided by a stick introduced into a nest 
opening) or inactive (when there was no response to this stimulus or no observed signs of ant activity). Only nests with active colonies were used because of the cleaning and maintenance activities by worker ants for the upkeep of trails and nest mounds.

Nests were also classified as mature (nest mound $\geq$ $15 \mathrm{~m}^{2}$ ) or immature (nest without one big mound, with dispersed small mounds). The species of Atta that were registered were: A. cephalotes, A. laevigata and A. sexdens, with this last species being the most common ( $80 \%$ of active colonies). The average area covered by mature nests was $40 \mathrm{~m}^{2}( \pm 15.7)$, with an estimated volume of removed soil of $6.9 \mathrm{~m}^{3}( \pm 3.2)$.

2.4. Statistical Analyses. The effect of ant nests on the quantity of combustible material was evaluated using regressions with distance from nest as the independent variable and the fuel parameters (height of small woody debris and weight of leaf litter) as dependent variables. The distance from nest was defined as the distance to the edge of the mound.

In order to test the relationship between nest presence and unburned vegetation, the cumulative percentage of unburned area was calculated at $5 \mathrm{~m}$ intervals from each active ant nest. It was then possible to conduct linear regressions using distance from nest as an independent variable and unburned area (log-transformed, base 10) as a dependent variable. Linear regressions were used to test the effects of distance from forest edge on nest number and unburned area.

\section{Results}

3.1. Nests as Inhibitors of Fire Spread. The average height of small woody debris on nests was $4.1 \mathrm{~cm}( \pm 2.1)$. However, on the forest floor, the values were highly variable. In general, fuel height increased with increasing distance from the nest (Figure 1).

Leaf litter mass also increases with distance from nest (Figure 1). The least amount of leaf litter was documented on top of nest mounds ( $33.8 \pm 136.1 \mathrm{~g})$, and the greatest amount on the forest floor $15 \mathrm{~m}$ from ant nests $(55.1 \pm 12.1 \mathrm{~g})$.

The average area of uncovered soil on top of ant nests was $1.58( \pm 0.2) \mathrm{m}^{2}$, which was significantly greater when compared to that near or around ant nests $\left(0.41 \pm 0.2 \mathrm{~m}^{2}\right.$; $t=-9,116 ; P=0,000 ; N=15)$.

The area of uncovered soil on top of mounds and foraging trails averaged $19 \mathrm{~m}^{2}$ per nest. Considering the number of nests with active colonies (269) inventoried in the 150 ha block, it can be inferred that 0.53 ha (or $0.35 \%$ ) would be under the protection of ants nests, if in fact all the colonies had reached maturity.

3.2. Relationship between Nest Abundance and Unburned Areas. Between 60 to $90 \%$ of the area that was unburned during the experimental understory fires occurred within approximately $30 \mathrm{~m}$ of leaf-cutter ant nests and declined with increasing distance from nests (Figure 2).

The number of nests diminished with increasing distance from the edge (Figure 3). Also it was noted that, with the

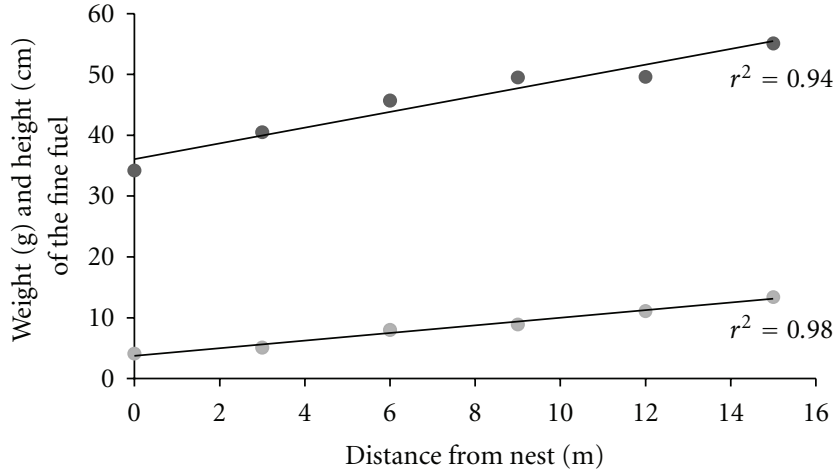

Figure 1: Litter mass $(\mathrm{g})$ and height $(\mathrm{cm})$ of small woody debris $(\leq 5 \mathrm{~cm})$ as a function of distance from leaf-cutter ant nests in a forest at the Amazon-Cerrado transition. Black circles: litter mass; gray circles: height of small woody debris, $N=6$.

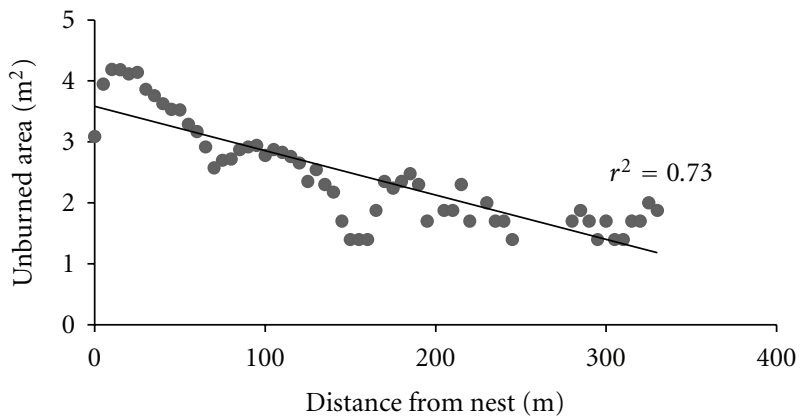

(a) 2004

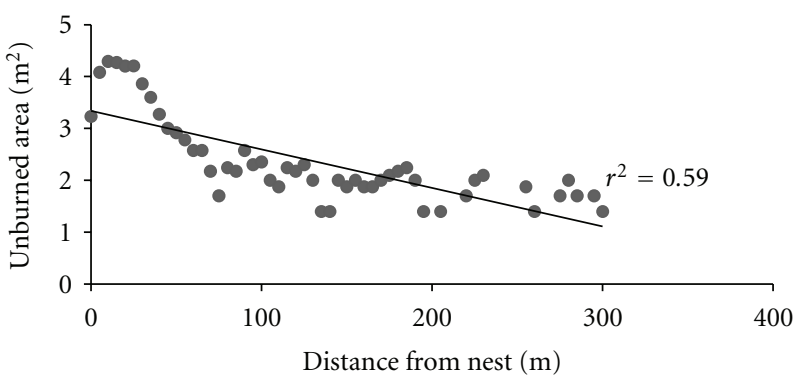

(b) 2005

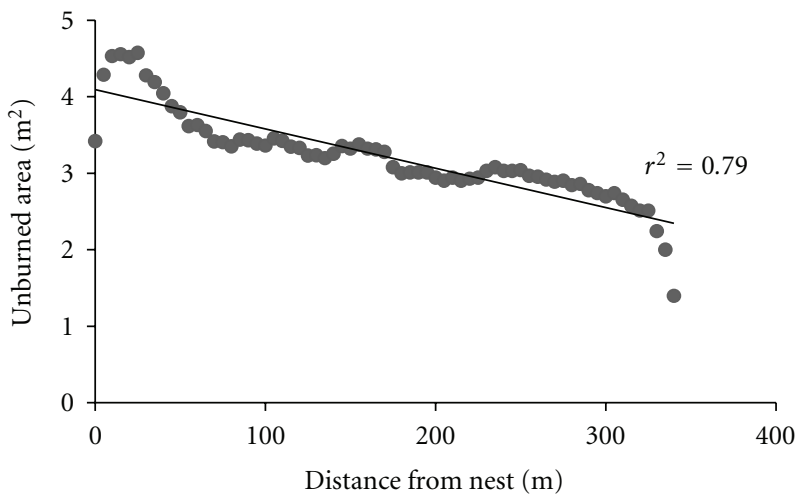

(c) 2006

FIGURE 2: Relationship between unburned area and distance to nests in the 50 ha thrice-burned plot in a transitional forest near the Amazon-Cerrado boundary, $N=200$. 


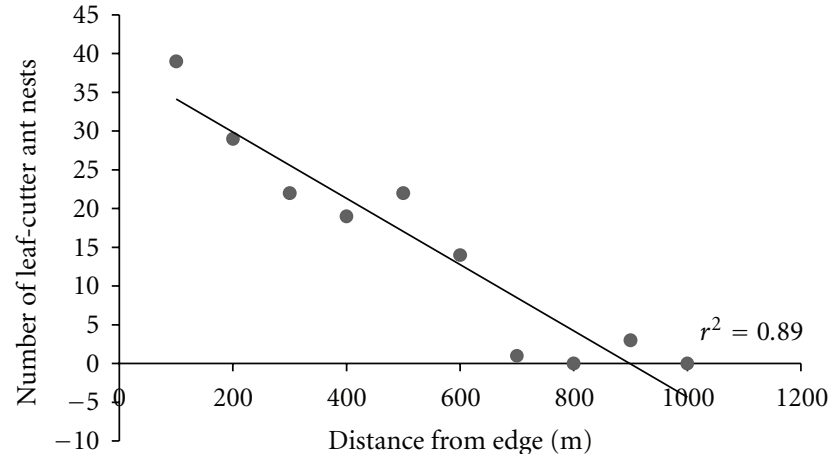

Figure 3: Number of leaf-cutter ant nests in relation to distance from the edge of a transitional forest at the Amazon-Cerrado boundary, $N=10$.

exception of the first experimental fire in 2004, there was more unburned area at the edge that in the forest interior (Figure 4).

\section{Discussion}

The reduction in spread of low-intensity fires (small flame heights $\sim 30 \mathrm{~cm}$ ) and thereby burned area, is associated with the presence of ant nests. Although this study primarily demonstrates a correlation, the shortage of leaf litter and small-medium woody debris (combustible material), provoked by leaf-cutter ant bioperturbation, likely provides a mechanism whereby fire spread of low-intensity fires is diminished. In this transitional forest, fuel quantity can be more important in determining fire intensity and spread than relative humidity and other microclimate variables, which control fire behavior during the dry season of a typical humid Amazon forest [38-41]. In fact, fuel mass determined fire behavior in this transitional forest at the AmazonCerrado boundary, where a slight decline in fuels after two annual burns limited fire intensity and spread rates [35].

The capacity of leaf-cutter ants to diminish available surface fuels at a fine scale can be extended to the landscape scale where ant nest density is high, as is the case at forest edges [22, 29-31]. The most important result of this study is the documentation that ant nests and trails can function as effective firebreaks at forest edges, which have been traditionally known to be vulnerable to fire entry and spread [42-44]. Edge formation causes alterations in microclimate-such as a decline in humidity and increase in temperature and wind speed-all of which promote fuel drying and fire spread [45]. Further, edge formation dries out adjacent forest fragments and increases available surface fuels, as much as from leaf and branch fall due to plants that are subjected to increased wind exposure $[46,47]$, as from the forest damage caused by timber removal in these regions $[44,48]$.

Given this context, populations of leaf-cutter ants may increase, as invertebrate herbivores are repeatedly observed more in edges than forest interiors $[22,29,30]$. Ant nest abundance in these edge areas must be related, in part, to the founding queens' choice [49], which could be driven by their attraction to sunny areas when in nuptial flight.

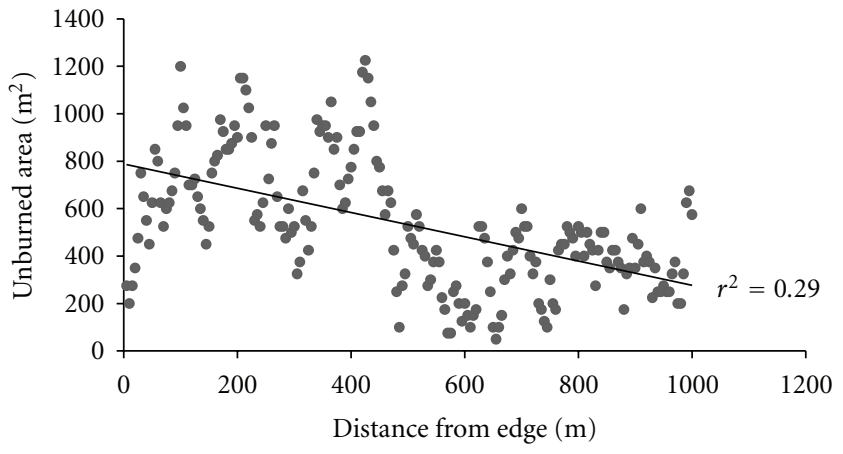

(a) 2004

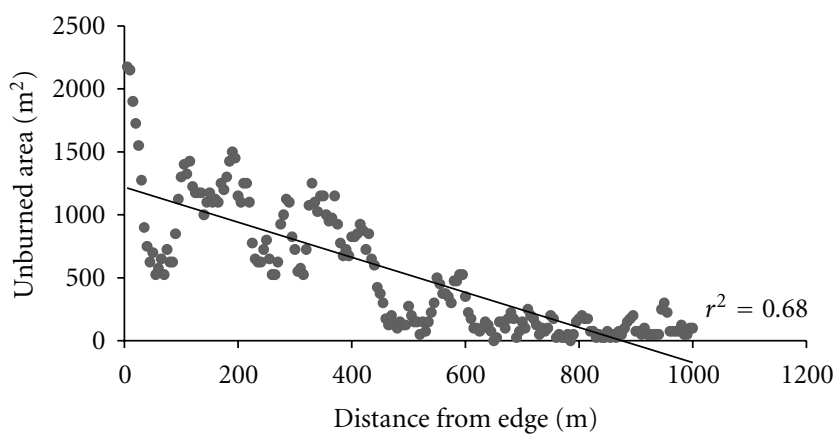

(b) 2005

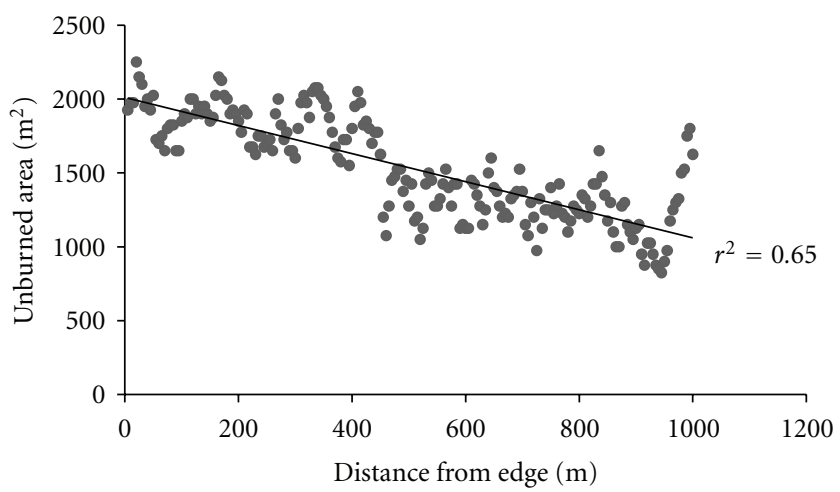

(c) 2006

FIGURE 4: Relationship between unburned area and edge distance in the 50 ha annual burn plot in a transitional forest at the AmazonCerrado boundary, $N=4$.

Beyond the founding queen's dispersal choice, the majority of ant nests in border areas also could be explained by greater colony survival rates in these locations. Leaf-cutter ants require a certain quantity of solar radiation to reach their mounds, and, because of this, they may establish better in locations without shade $[14,32]$.

Leaf-cutter ant nests occupy large areas, and their populations have a high turnover rate $[21,50]$. This means that, beyond the area free of debris that is potentially important in protecting against fire, these deep nests represent frequent and intense disturbance covering large areas in the forest, beyond even what is visible. Fire-induced mortality rate of plants from these mimicked understory fires, calculated for this transitional forest, was the lowest documented for Amazon forests [35]. A possible explanation for this low 
mortality was the lowered flammability related to a lack of fuel mass during a third annual experimental burn [35], which limited ignition of larger woody debris or standing dead wood. The degree of flammability depends on the rate of accumulation of fuels and production of litterfall [51] which, in the study area, was substantially lower than in other Amazon forests [35].

The reduction in fuels close to leaf-cutter ant nests could also be influenced by other factors, such as the selectivity of these ants to nest in areas with low leaf litter and woody debris. However, even if other factors contribute to lowered forest flammability and attenuate the damaging effects of fire, the contribution of ant nests in protecting nearby vegetation from low-intensity fires cannot be ignored. This study demonstrates that the behavior of these leaf-cutter ants diminishes the volume of fuels in the environment, by creating, establishing, and maintaining their conspicuous nests in the surface soil of a transitional forest at the AmazonCerrado boundary.

This study provides new insights into fire ecology from Amazon studies because the nest effects are off-setting, so that edge areas with lots of nests may not be more susceptible to low-intensity fire than interior plots, as had previous been thought.

Further study should investigate how effective ant nests and trails are at inhibiting more intense or faster fires, such as those observed during more severe droughts. Atta is a neotropical genus, and does not have an equivalent organism in well-studied fire-prone ecosystems in Old World systems, as South Africa or Australia; future study may also reveal if there are analog behaviors in Old World invertebrate species. It can be hypothesized from this work that increasing fire frequency, associated with an expanding agricultural frontier, will select for Atta species over wood-building taxa, due to their fire-proof construction materials and firebreak trails. This selection may leave lasting effects on arthropod community structure and composition. Given the inherent fire-protection that Atta provides, this provides an incentive for farmers and ranchers to avoid using insecticides at agriculture-forest edges. Further study should document the abundance and distribution of Atta colonies in burned-over forests through time and their influence on fire behavior of more intense, repeated fires.

\section{Acknowledgments}

The authors are grateful to the Woods Hole Research Center and Instituto de Pesquisa Ambiental da Amazônia (IPAM) for institutional support. Special thanks are due to Grupo Amaggi, who invited this research to be conducted on their farm and provided infrastructure support. The authors especially thank IPAM staff Darlisson Nunes, Osvaldo Portela, Raimundo Mota Quintino, Roberto Baena, Joelson Carvalho Serrão, Aderlan Pedroso, and Adriano Portela for assistance during fieldwork. Special acknowledgment is due to Paul Lefebvre for map elaboration and Daniel Nepstad for his contribution to the overall study. Eric Davidson provided helpful comments on earlier versions of the paper. Financial support came from the Programa de Bolsas de Estudo para a
Conservação da Amazônia of Instituto Internacional de Educação no Brasil (BECA- IEB) and Fundação de Amparo a Pesquisa do Estado da Bahia (FAPESB). Financial support for the project at large was provided by the David and Lucile Packard Foundation, NASA LBA-ECO program, and NSF Biocomplexity in the Environment and Ecosystems programs.

\section{References}

[1] J. M. Cherret, "History of the leaf-cutting ant problem," in Fire Ants and Leaf-Cutting Ants: Biology and Management, C. S. Lofgren and R. K. Vander Meer, Eds., pp. 10-17, Westview Press, Boulder, Colo, USA, 1986.

[2] J. M. Cherret, "Leaf-cutting ants, biogeographical studies," in Ecosystem of the World 14 b, Tropical Rain Forest Ecosystem, $\mathrm{H}$. Lieth and M. Werger, Eds., pp. 437-486, Elsevier, Amsterdam, The Netherlands, 1989.

[3] P. Moutinho, D. C. Nepstad, and E. A. Davidson, "Influence of leaf-cutting ant nests on secondary forest growth and soil properties in Amazonia," Ecology, vol. 84, no. 5, pp. 12651276, 2003.

[4] L. V. Verchot, P. R. Moutinho, and E. A. Davidson, "Leafcutting ant (Atta sexdens) and nutrient cycling: deep soil inorganic nitrogen stocks, mineralization, and nitrification in Eastern Amazonia," Soil Biology and Biochemistry, vol. 35, no. 9, pp. 1219-1222, 2003.

[5] M. Garrettson, J. F. Stetzel, B. S. Halpern, D. J. Hearn, B. T. Lucey, and M. J. Mckone, "Diversity and abundance of understorey plants on active and abandoned nests of leaf-cutting ants (Atta cephalotes) in a Costa Rican rain forest," Journal of Tropical Ecology, vol. 14, no. 1, pp. 17-26, 1998.

[6] A. G. Farji-Brener and L. Ghermandi, "Influence of nests of leaf-cutting ants plant species diversity in road verges of northern Patagonia," Journal of Vegetation Science, vol. 11, no. 3, pp. 453-460, 2000.

[7] A. G. Farji-Brener and A. E. Illes, "Do leaf-cutting ant nests make 'bottom-up' gaps in neotropical rain forests?: a critical review of the evidence," Ecology Letters, vol. 3, no. 3, pp. 219227, 2000.

[8] A. G. Farji-Brener, "The effect of abandoned leaf-cutting ant nests on plant assemblage composition in a tropical rainforest of Costa Rica," Ecoscience, vol. 12, no. 4, pp. 554-560, 2005.

[9] M. M. Corrêa, P. S. D. Silva, R. Wirth, M. Tabarelli, and I. R. Leal, "How leaf-cutting ants impact forests: drastic nest effects on light environment and plant assemblages," Oecologia, vol. 162, no. 1, pp. 103-115, 2010.

[10] L. D. S. L. Sternberg, M. C. Pinzon, M. Z. Moreira, P. Moutinho, E. I. Rojas, and E. A. Herre, "Plants use macronutrients accumulated in leaf-cutting ant nests," Proceedings of the Royal Society B, vol. 274, no. 1608, pp. 315-321, 2007.

[11] L. Sousa-Souto, J. H. Schoereder, and C. E. G. R. Schaefer, "Leaf-cutting ants, seasonal burning and nutrient distribution in Cerrado vegetation," Austral Ecology, vol. 32, no. 7, pp. 758765, 2007.

[12] K. S. Carvalho, Influências dos ninhos de saúva (Formicidae: Attini) na nutrição, crescimento e proteção da vegetação contra o fogo, em uma floresta de transição Amazônia-Cerrado, Ph.D. dissertation, Museu Paraense Emílio Goldi, Belém, Brazil, 2009.

[13] F. A. M. Mariconni, As Saúvas, Universidade de São Paulo, São Paulo, Brazil, Agronômica Ceres edition, 1970. 
[14] N. A. Weber, Gardening Ants: The Attines, American Philosophical Society, Philadelphia, Pa, USA, 1972.

[15] B. Holldobler and E. O. Wilson, The Ants, Harvard University Press, Cambridge, Mass, USA, 1990.

[16] A. A. Moreira, L. C. Forti, M. A. C. Boaretto, A. P. P. Andrade, J. F. S. Lopes, and V. M. Ramos, "External and inter-nal structure of Atta bisphaerica Forel (Hymenoptera: Formicidae) nests," Journal of Applied Entomology, vol. 128, no. 3, pp. 204-211, 2004.

[17] M. Autuori, "Contribuição para o conhecimento da saúva," Arquivos do Instituto Biológico, vol. 18, pp. 39-70, 1947.

[18] E. Amante, "Nota prévia sobre a estrutura do ninho de uma nova formiga saúva (Atta sp.) (Hymenoptera: Formicidae)," Biológico, vol. 30, pp. 96-97, 1964.

[19] A. Alvarado, C. Berish, and F. Peralta, "Leaf-cutter ant (Atta cephalotes) Influence on the morphology of andepts in Costa Rica," Soil Science Society America Journal, vol. 45, pp. 790-794, 1981.

[20] A. G. Farji-Brener and J. Silva, "Leaf cutting ants and soil fertility in a well-drained savanna in western Venezuela," Biotropica, vol. 27, pp. 250-253, 1995.

[21] R. Wirth, H. Herz, R. J. Ryel, W. Beyschlag, and B. Holldobler, Herbivory of Leaf-Cutting Ants: A Case Study on Atta colombica in the Tropical Rainforest of Panama, Springer, Berlin, Germany, 2003.

[22] P. Urbas, M. V. Araújo Jr., I. R. Leal, and R. Wirth, "Cutting more from cut forests: edge effects on foraging and herbivory of leaf-cutting ants in Brazil," Biotropica, vol. 39, no. 4, pp. 489-495, 2007.

[23] N. A. Costa, L. H. Vasconcelos, H. M. E. Vieira-Neto, and M. E. Bruna, "Do herbivores exert top-down effects in Neotropical savannas? Estimates of biomass consumption by leaf-cutter ants," Journal of Vegetation Science, vol. 19, no. 6, pp. 849-854, 2008.

[24] J. Navarro and K. Jaffé, "On the adaptive value of nest features in the grass-cutting ant Acromyrmex landolti," Biotropica, vol. 17, pp. 347-348, 1985.

[25] H. G. Fowler, "Distribution patterns of Paraguayan leafcutting ants (Atta and Acromyrmex) (Formicidae: Attini)," Studies Neotropical Fauna and Environment, vol. 18, pp. 121-138, 1983.

[26] H. L. Vasconcelos and J. M. Cherrett, "Changes in leaf-cutting ant populations (Formicidae: Attini) after the clearing of mature forest in Brazilian Amazonia," Studies on Neotropical Fauna and Environment, vol. 30, no. 2, pp. 107-113, 1995.

[27] M. Rao, "Variation in leaf-cutter ant (Atta sp.) densities in forest isolates: the potential role of predation," Journal of Tropical Ecology, vol. 16, no. 2, pp. 209-225, 2000.

[28] B. A. Santos, C. A. Peres, M. A. Oliveira, A. Grillo, C. P. Alves-Costa, and M. Tabarelli, "Drastic erosion in functional attributes of tree assemblages in Atlantic forest fragments of northeastern Brazil," Biological Conservation, vol. 141, no. 1, pp. 249-260, 2008.

[29] V. S. Barbosa, I. R. Leal, L. Iannuzzi, and J. Almeida-Cortez, "Distribution pattern of herbivorous insects in a remnant of Brazilian Atlantic forest," Neotropical Entomology, vol. 34, no. 5, pp. 701-711, 2005.

[30] R. Wirth, S. T. Meyer, W. R. Almeida, M. V. Araujo Jr., V. S. Barbosa, and I. R. Leal, "Increasing densities of leaf-cutting ants (Atta spp.) with proximity to the edge in a Brazilian Atlantic forest," Journal of Tropical Ecology, vol. 23, no. 4, pp. 501-505, 2007.
[31] S. T. Meyer, I. R. Leal, and R. Wirth, "Persisting Hyperabundance of Leaf-cutting Ants (Atta spp.) at the edge of an old atlantic forest fragment," Biotropica, vol. 41, no. 6, pp. 711-716, 2009.

[32] K. Jaffe and E. Vilela, "On nest densities of the leaf-cutting ant Atta cephalotes in tropical primary forest," Biotropica, vol. 21, no. 3, pp. 234-236, 1989.

[33] A. G. Farji-Brener, "Why are leaf-cutting ants more common in early secondary forests than in old-growth tropical forests? An evaluation of the palatable forage hypothesis," Oikos, vol. 92, no. 1, pp. 169-177, 2001.

[34] D. Oren, Portfolio de Áreas Importantes para a Conservação da Biodiversidade Brasileira: uma Análise por Ecorregião, The Nature Conservancy, Brasília, Brazil, 2005.

[35] J. R. K. Balch, D. C. Nepstad, P. M. Brando et al., "Negative fire feedback in a transitional forest of southeastern Amazonia," Global Change Biology, vol. 14, no. 10, pp. 2276-2287, 2008.

[36] L. Oksanen, "Logic of experiments in ecology: is pseudoreplication a pseudoissue?" Oikos, vol. 94, no. 1, pp. 27-38, 2001.

[37] P. Van Mantgem, M. Schwartz, and M. Keifer, "Monitoring fire effects for managed burns and wildfires: coming to terms with pseudoreplication," Natural Areas Journal, vol. 21, no. 3, pp. 266-273, 2001.

[38] D. Nepstad, P. Lefebvre, U. L. Da Silva et al., "Amazon drought and its implications for forest flammability and tree growth: a basin-wide analysis," Global Change Biology, vol. 10, no. 5, pp. 704-717, 2004.

[39] D. Ray, D. Nepstad, and P. Moutinho, "Micrometeorological and canopy controls of fire susceptibility in a forested Amazon landscape," Ecological Applications, vol. 15, no. 5, pp. 1664-1678, 2005.

[40] G. M. Blate, "Modest trade-offs between timber management and fire susceptibility of a Bolivian semi-deciduous forest," Ecological Applications, vol. 15, no. 5, pp. 1649-1663, 2005.

[41] A. Alencar, D. Nepstad, and M. Del Carmen Vera Diaz, "Forest understory fire in the Brazilian Amazon in ENSO and non-ENSO years: area burned and committed carbon emissions," Earth Interactions, vol. 10, no. 6, pp. 1-17, 2006.

[42] M. A. Cochrane and M. D. Schulze, "Fire as a recurrent event in tropical forests of the eastern Amazon: effects on forest structure, biomass, and species composition," Biotropica, vol. 31, no. 1, pp. 2-16, 1999.

[43] M. A. Cochrane, A. Alencar, M. D. Schulze et al., "Positive feedbacks in the fire dynamic of closed canopy tropical forests," Science, vol. 284, no. 5421, pp. 1832-1835, 1999.

[44] D. C. Nepstad, A. Veríssimo, A. Alencar et al., "Large-scale impoverishment of amazonian forests by logging and fire," Nature, vol. 398, no. 6727, pp. 505-508, 1999.

[45] V. Kapos, "Effects of isolation on the water status of forest patches in the Brazilian Amazon," Journal of Tropical Ecology, vol. 5, no. 2, pp. 173-185, 1989.

[46] W. F. Laurance, L. V. Ferreira, J. M. Rankin-De Merona, S. G. Laurance, R. W. Hutchings, and T. E. Lovejoy, "Effects of forest fragmentation on recruitment patterns in Amazonian tree communities," Conservation Biology, vol. 12, no. 2, pp. 460-464, 1998.

[47] H. L. Vasconcelos and F. J. Luizão, "Litter production and litter nutrient concentrations in a fragmented amazonian landscape," Ecological Applications, vol. 14, no. 3, pp. 884-892, 2004.

[48] C. Uhl and J. B. Kauffman, "Deforestation effects on fire susceptibility and the potential response of tree species to fire in the rain forest of the eastern Amazon," Ecology, vol. 71, pp. 437-449, 1990. 
[49] H. L. Vasconcelos, E. H. M. Vieira-Neto, F. M. Mundim, and E. M. Bruna, "Roads alter the colonization dynamics of a keystone herbivore in neotropical savannas," Biotropica, vol. 38, no. 5, pp. 661-665, 2006.

[50] I. Perfecto and J. Vandermeer, "Distribution and turnover rate of a population of Atta cephalotes in a tropical rain forest in Costa Rica," Biotropica, vol. 25, no. 3, pp. 316-321, 1993.

[51] D. Nepstad, P. Moutinho, M. B. Dias-Filho et al., "The effects of partial throughfall exclusion on canopy processes, aboveground prodution, and biogeochemistry of the Amazon forest," Journal of Geophysical Research, vol. 107, pp. 1-18, 2002. 

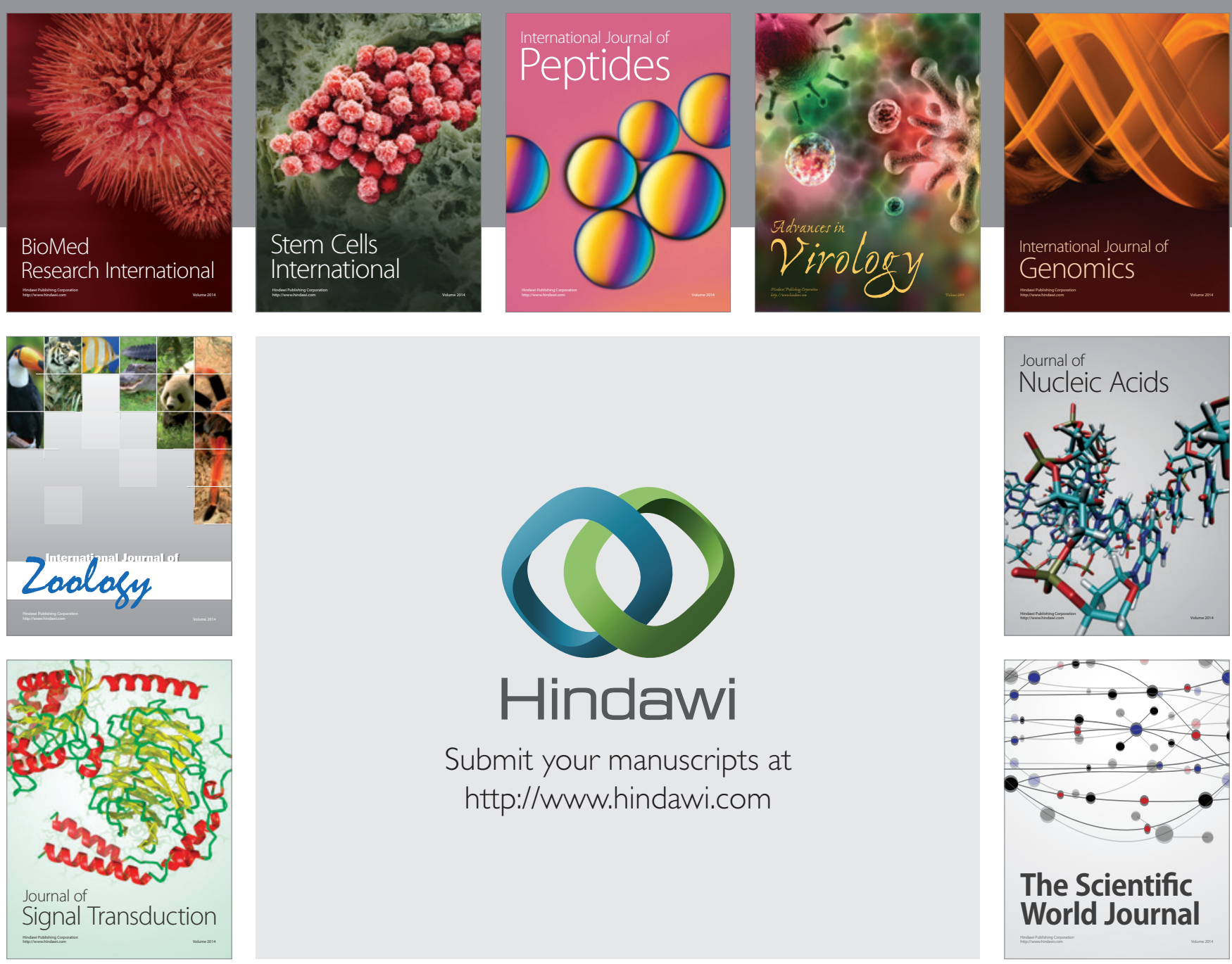

Submit your manuscripts at

http://www.hindawi.com
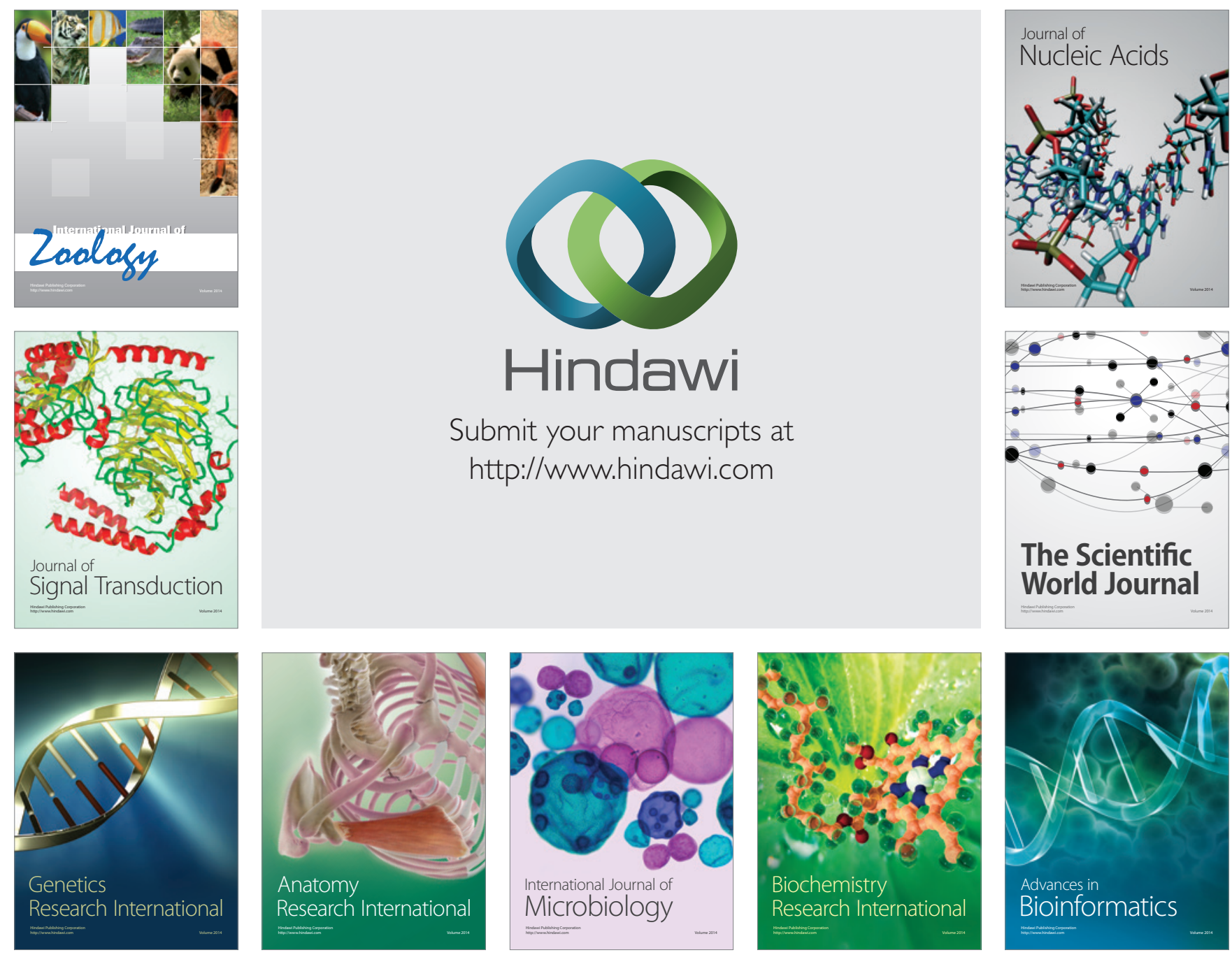

The Scientific World Journal
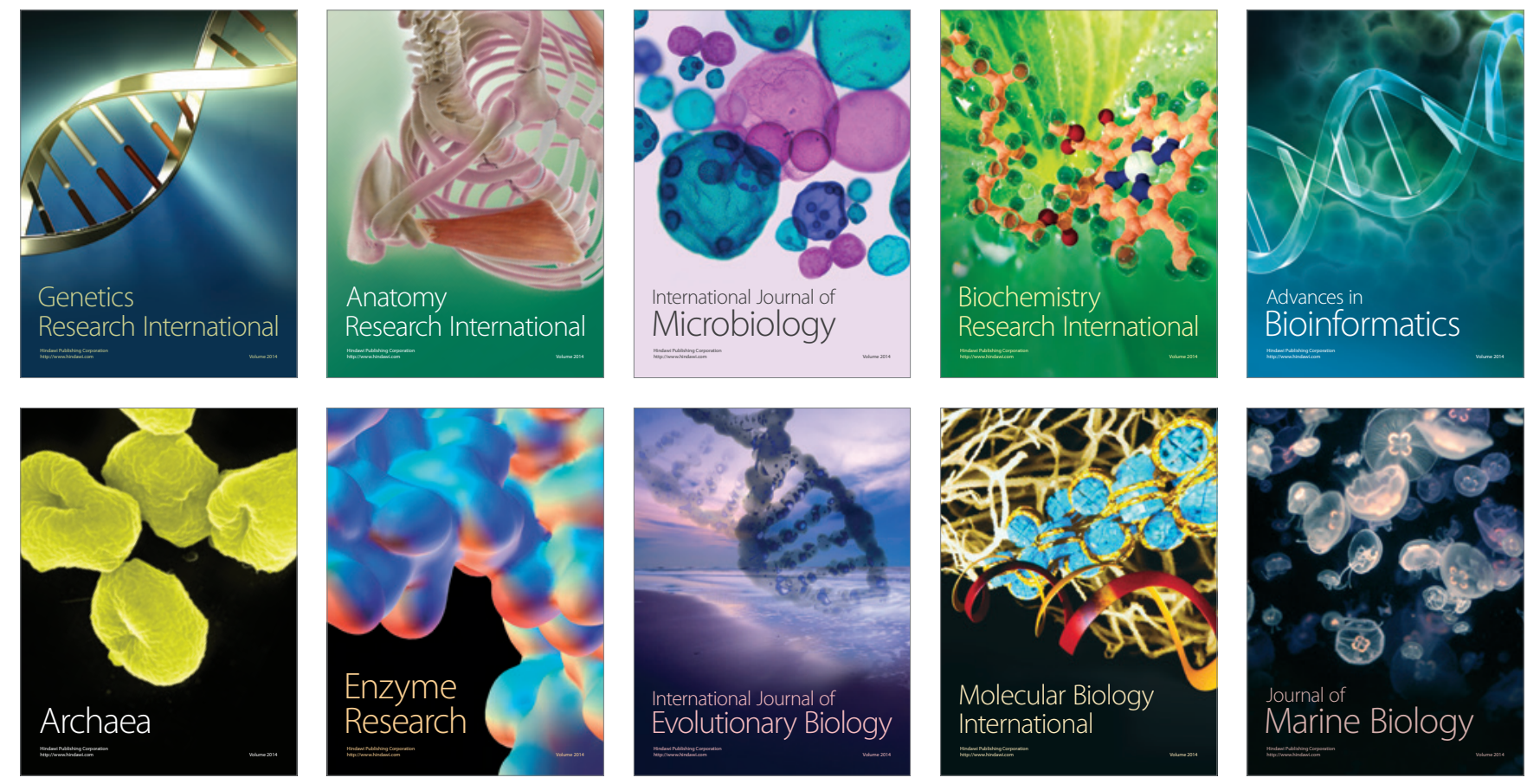